\title{
Effectiveness of omalizumab in children and adolescents with uncontrolled allergic asthma: a case series from Poland
}

\author{
Anna Sztafińskaํ, Mikołaj Gwardys², Daniela Podlecka ${ }^{1}$ Ewa Mospinek ${ }^{1}$, Iwona Stelmach ${ }^{1}$
}

${ }^{1}$ Department of Paediatrics and Allergy, Medical University of Lodz, Copernicus Memorial Hospital, Lodz, Poland

2Department of Paediatrics and Immunology with Nephrology Unit, Polish Mother's Memorial Hospital Research Institute, Lodz, Poland

Adv Dermatol Allergol 2021; XXXVIII (3): 427-432

DOI: https://doi.org/10.5114/ada.2021.107929

\begin{abstract}
Introduction: Omalizumab has been successfully used as a supplementary therapy to improve asthma control in children aged $\geq 6$ years with moderate or severe persistent allergic asthma.

Aim: To evaluate effectiveness of omalizumab in children and adolescents with uncontrolled allergic asthma.

Material and methods: Seventeen children and adolescents aged 8-16, treated with omalizumab from 2011 until now, were enrolled into the retrospective, open, uncontrolled, observational study. The effectiveness of therapy, asthma control, quality of life, exacerbation rate, corticosteroid use, were assessed after 16, 52 and 104 weeks of treatment and after omalizumab cessation.

Results: The response to treatment was assessed as excellent (9 patients) and good (6 patients), according to global evaluation of treatment effectiveness (GETE). A statistically significant decrease in use of oral corticosteroids (OCS) and leukotriene receptor antagonists (LTRAs) was observed. The doses of inhaled corticosteroids (ICS) decreased significantly (the mean dose of ICS converted to a dose of budesonide before treatment was $1503.53 \mu \mathrm{g} /$ day versus $903.53 \mu \mathrm{g}$ after discontinuation). The mean asthma control questionnaire (ACQ) value decreased from 2.10 to 0.84 points and the mean mini asthma quality of life questionnaire (miniAQLQ) outcome increased from 4.37 to 6.1 points. The mean number of exacerbations decreased from 5.59 to 0.53 per year.

Conclusions: Our results are supportive of the existing evidence that omalizumab therapy improves asthma control, reduces OCS and ICS use, decreases exacerbations in children and adolescents with severe/moderate uncontrolled allergic asthma.
\end{abstract}

Key words: asthma, omalizumab, anti-lgE therapy, children.

\section{Introduction}

Asthma is the most common lung disease in children and there is an increasing trend in the prevalence of asthma among children and adolescents. As shown in a CDC National Surveillance of Asthma report, the frequency of asthma attacks and the necessity of emergency visits is higher in children as compared to adults [1]. There are a lot of factors that cause poor asthma control in children. Most of them can be easily modifiable: poor inhaler technique, undertreatment with controller medications. Other factors are hardly modifiable: educational and financial status of caregivers, exposure to tobacco smoke, depression in children and/or their caregivers [2, 3].
Uncontrolled asthma may result in a higher risk of exacerbations, higher rate of hospitalizations, impairs children's and their caregivers' quality of life and increases the risk of morbidity. Omalizumab, a monoclonal anti-immunoglobulin E antibody, blocks free-circulating IgE inhibiting their binding to the specific receptors but does not displace them from the connection with specific receptors on target cells. It has been successfully used as a supplementary therapy to improve asthma control in children aged $\geq 6$ years with severe persistent allergic asthma who experience frequent symptoms and have asthma exacerbation despite the use of high-dose inhaled corticosteroids (ICS) and long-acting $\beta 2$-agonists (LABA) [4]. The efficacy and safety of anti-IgE therapy

Address for correspondence: Iwona Stelmach MD, PhD, Prof., Department of Paediatrics and Allergy, Medical University of Lodz, Korczak Pediatric Center, 71 Piłsudskiego St, 90-329 Lodz, Poland, phone: +48 422074726, e-mail: alergol@kopernik.lodz Received: 24.04.2019, accepted: 14.01.2020. 
was documented in several studies [5-11], however the observational, real-life studies including asthma control after omalizumab discontinuation are still poor due to a relatively short period of anti-lgE therapy use.

As far as we are concerned, our centre has the greatest experience in omalizumab therapy in children in Poland. In this article we present evaluation of effectiveness of omalizumab therapy in children and adolescents, focusing on asthma control after cessation of biological treatment.

\section{Aim}

Here, we report the outcomes of add-on omalizumab treatment in children and adolescents from Poland. We evaluated asthma control, quality of life, use of inhaled (ICS) and oral corticosteroids (OCS), lung function and the number of exacerbations during therapy and after treatment cessation.

\section{Material and methods}

Seventeen children and adolescents from our Paediatric Allergy Clinic treated with omalizumab from 2011 until now, were enrolled into this retrospective, open, uncontrolled, observational study. Patients were aged 8-16 years on the treatment onset. The diagnosis of asthma was universally established by the allergy specialists according to the standard definitions of diseases in GINA guidelines. All patients fulfilled the criteria for anti-lgE therapy; none of the participants had a contraindication for the treatment. All patients had multiple allergies; the most clinically important allergens were: house dust mite, grass pollen and cat dander. Five patients had been previously qualified for specific immunotherapy SIT (data from medical history), but the maintenance dose could not be reached because of recurrent asthma exacerbations, and SIT had to be discontinued. At least 6 months before starting treatment, patients underwent long-term therapy with high-dose ICS in combination with $L A B A$ and/or leukotriene receptor antagonists (LTRAs). The adherence to anti-asthmatic therapy was systematically assessed before and after the initiation of treatment. Omalizumab was administered according to a dosage table considering the patient's body weight and baseline total serum IgE levels. Demographic and clinical characteristics of the patients are shown in Table 1.

The posology of Xolair ${ }^{\oplus}$ was as follows:

- 600 mg every 2 weeks (Q14d), 4 patients;

Table 1. Descriptive statistics for numerical traits in the studied patients

\begin{tabular}{|c|c|c|c|c|c|c|}
\hline \multirow[t]{2}{*}{ Investigated trait } & \multicolumn{5}{|c|}{ Statistical parameter } & \multirow{2}{*}{$\begin{array}{l}\text { Level of statistical } \\
\text { significance } \\
(p \text {-value })\end{array}$} \\
\hline & M & $\mathrm{Me}$ & SD & $95 \% \mathrm{Cl}$ & Min.-max. & \\
\hline Age at the beginning of treatment [years] & 12.36 & 12.25 & 1.84 & $11.42-13.31$ & $8.83-16.83$ & - \\
\hline Therapy duration [months] & 30.29 & 32.00 & 10.63 & $24.83-35.76$ & $12-48$ & - \\
\hline $\begin{array}{l}\text { ICS before treatment (converted to a dose } \\
\text { of budesonide) }[\mu \mathrm{g}]\end{array}$ & 1503.53 & 1600 & 581.22 & $\begin{array}{c}1204.70- \\
1802.36\end{array}$ & $320-2400$ & 0.002 \\
\hline $\begin{array}{l}\text { ICS after treatment (converted to a dose } \\
\text { of budesonide) }[\mu \mathrm{g}]\end{array}$ & 903.53 & 800 & 437.96 & $678.35-1128.71$ & $320-1600$ & \\
\hline Asthma exacerbations before treatment per year & 5.59 & 4 & 4.78 & $3.13-8.05$ & $2-20$ & $<0.001$ \\
\hline $\begin{array}{l}\text { Asthma exacerbations after cessation } \\
\text { of omalizumab per year }\end{array}$ & 0.53 & 0 & 0.94 & $0.04-1.01$ & $0-3$ & \\
\hline Level of total IgEs [IU/ml] & 805.33 & 913 & 419.06 & $589.87-1020.80$ & $116.70-1414.00$ & - \\
\hline $\mathrm{FEV}_{1}$ best/pred. before treatment (\%) & 97.51 & 94.60 & 17.04 & $88.74-106.27$ & 69.10-137.30 & 0.528 \\
\hline $\mathrm{FEV}_{1}$ best/pred. after treatment (\%) & 103.55 & 103.00 & 14.64 & $96.02-111.08$ & $83.40-133.00$ & \\
\hline FVC best/pred. before treatment (\%) & 104.65 & 103.80 & 15.79 & $96.23-113.07$ & $78.20-140.00$ & 0.326 \\
\hline FVC best/pred. after treatment (\%) & 109.15 & 109.00 & 14.57 & $101.66-116.64$ & $79.30-140.00$ & \\
\hline ACQ results before treatment & 2.10 & 1.90 & 0.73 & $1.73-2.48$ & $1.28-4.10$ & $<0.001$ \\
\hline ACQ results after 1 year & 0.84 & 0.57 & 0.68 & $0.47-1.22$ & $0.14-2.14$ & \\
\hline MiniAQLQ results before treatment & 4.37 & 4.75 & 0.80 & $3.96-4.78$ & $1.90-5.07$ & $<0.001$ \\
\hline MiniAQLQ results after 1 year & 6.10 & 6.40 & 0.73 & $5.70-6.51$ & $4.47-6.80$ & \\
\hline
\end{tabular}

$M$ - mean, Me-median, SD - standard deviation, CI - confidence interval, ICS - inhaled corticosteroids, IgES - immunoglobulins class E, IU - international unit, FEV 1 - forced expiratory volume in 1 s, FVC - forced vital capacity, ACQ - Asthma Control Questionnaire, miniAQLQ - Mini Asthma Quality of Life Questionnaire. 
- 300 mg every 4 weeks (Q28d), 3 patients;

- 375 mg every 2 weeks (Q14d), 3 patients;

- 450 mg every 4 weeks (Q28d), 3 patients;

- 300 mg every 2 weeks (Q14d), 1 patient;

- 450 mg every 2 weeks (Q14d), 1 patient;

- 525 mg every 2 weeks (Q14d), 1 patient;

- 600 mg every 4 weeks (Q28d), 1 patient.

Children received omalizumab from 12 to 48 months and 4 children are still treated with anti-lgE therapy. The longest follow-up period (after treatment cessation) was 4.5 year.

The primary outcome/aim was to assess long-term effectiveness of anti-lgE therapy. The effectiveness of therapy was assessed on control visits after 16, 52 and 104 weeks of treatment, according to the Global Evaluation of Treatment Effectiveness (GETE scale) [12]. Patients whose treatment response was assessed as excellent or good, were qualified as responders, while these with moderate, poor or worse response were non-responders and discontinued the therapy.

The other outcomes included the asthma control based on Asthma Control Questionnaire (ACQ) and the quality of life with mini Asthma Quality of Life Questionnaire (miniAQLQ) [13]. The comparison of outcomes before treatment and on the last day of therapy was performed. Use of asthma controller medications and OCS was evaluated before the therapy, after the last dose of treatment and after omalizumab cessation. Lung function was assessed with spirometry, forced expiratory volume in $1 \mathrm{~s}\left(\mathrm{FEV}_{1}\right)$ and forced vital capacity (FVC) measurements at the beginning and on the day of omalizumab cessation were compared.

\section{Results}

Seventeen patients were qualified to the biological treatment with omalizumab in our clinic and four of them still continue the therapy. The first patient started treatment in August 2011. In March 2013 the program of treatment of severe IgE-dependent asthma with omalizumab, funded by the National Health Fund, was intro-

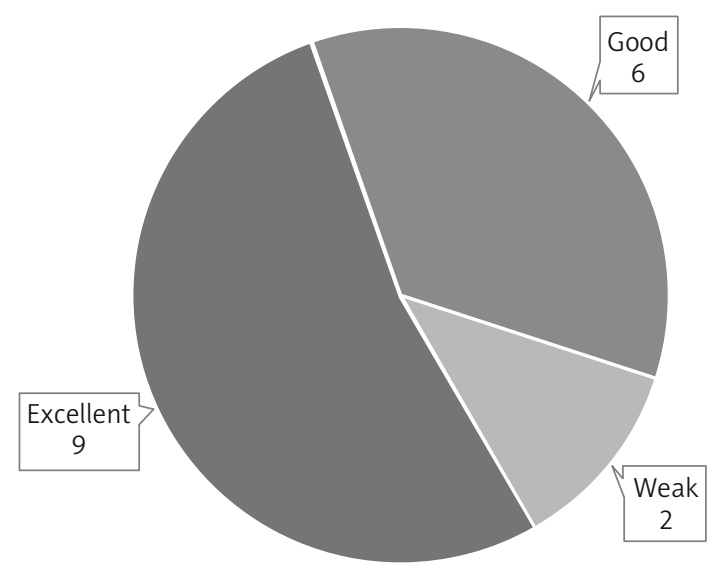

Figure 1. The studied patients' response to treatment according to the GETE scale $(n=17)$ duced in Poland and due to this fact, more patients could be qualified to this therapy. According to GINA guidelines, before the start of biological therapy, 6 patients received asthma treatment on step 5 and 11 patients on step 4. The mean time of treatment duration was 30.29 months. The patient who was qualified to omalizumab therapy as the first one, had also the longest time of the therapy (48 months). In 2018 the National Health Fund recommended stopping the treatment after 2 years and observing the patients for the next 12 months with the possibility to return to the therapy due to loss of asthma control. This is the explanation why in our group of patients the duration of the treatment is so different. The therapy was discontinued in 2 patients due to weak response (1 patient was withdrawn after 13 months and the second one after 17 months of treatment). In other patients the response to treatment was assessed as excellent ( 9 patients) and good (6 patients), according to the Global Evaluation of Treatment Effectiveness (GETE) scale (Figure 1). In our patients we observed a statistically significant decrease in use of OCS and LTRAs. Six patients were administered OCS before the start of the therapy, while none of them needed OCS after treatment (Figure 2), LTRAs were taken by 15 patients at the beginning of therapy but only 8 patients still continued this treatment after omalizumab cessation (Figure 3). The reduction in LABA use was also observed, however it did not reach statistical significance (Figure 4).

Doses of ICS used in our patients before and after therapy with omalizumab are converted to a dose of budesonide and presented in Table 1. The mean dose of ICS before treatment was 1503.53 mg/day vs. $903.53 \mu \mathrm{g}$ after discontinuation. All of our patients, including these two with weak response to treatment, were treated for at least 1 year. Improvement in lung function test outcomes, regarding FEV 1 and FVC, was observed (Table 1) but was not statistically significant. We estimated the outcomes of questionnaires used to assess asthma con-

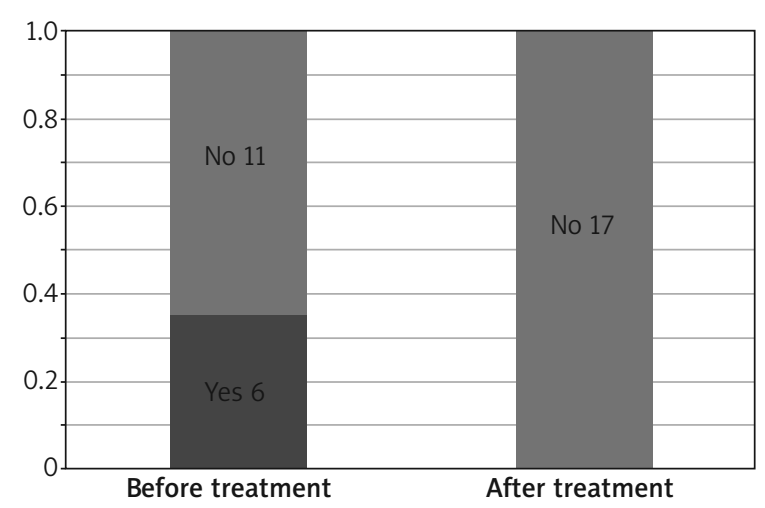

Figure 2. Administration of OCS to the studied patients $(p=0.035)$ 


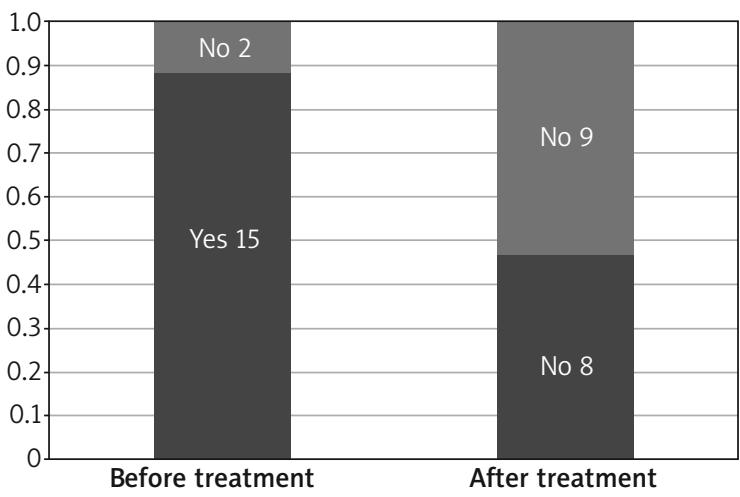

Figure 3. Administration of LTRA to the studied patients $(p=0.016)$

trol and patient's quality of life - ACQ and miniAQLQ before therapy and after 1 year and these data confirmed that biological treatment with omalizumab is effective and improves quality of life in asthmatic patients. The mean value ACQ decreased from 2.10 to 0.84 points and the mean value miniAQLQ increased from 4.37 to 6.1 points. The mean number of exacerbations statistically decreased from 5.59 to 0.53 per year. One patient who had excellent response to treatment, experienced about ten exacerbations during the first year after omalizumab cessation, but in the second year after treatment cessation the exacerbations decreased to one per year. Other patients had no exacerbations up to the end of the study.

\section{Discussion}

Omalizumab add-on treatment in the studied population resulted in clinically meaningful improvements in asthma control questionnaire (ACQ; mean change from baseline 2.1 points to 0.88 points after discontinuation) and patient health-related quality of life (miniAQLQ; mean change from baseline 4.37 points to 6.1 points after discontinuation). There was also a considerable reduction from baseline in the number of patients on OCS maintenance therapy $(n=6)$ to none after discontinuation of the treatment. We observed a clinically significant decrease in the ICS daily dose needed to control asthma from 1503.53 $\mu \mathrm{g}$ to $903.54 \mu \mathrm{g}$ of budesonide per day. We also proved that omalizumab add-on therapy reduced the number of clinically significant exacerbations from 5.59 at baseline to 0.53 per year after discontinuation. The study period including follow-up in the presented study is longer than in most of the previously presented studies. The outcomes of our study are similar to these included in systematic literature review performed by Corren et al. in children and adolescents with moderate-to-severe asthma [5]. The authors evaluated five real-world studies (RWS) - one retrospective observational analysis and four prospective cohort studies, with 312 patients in total, and three random-

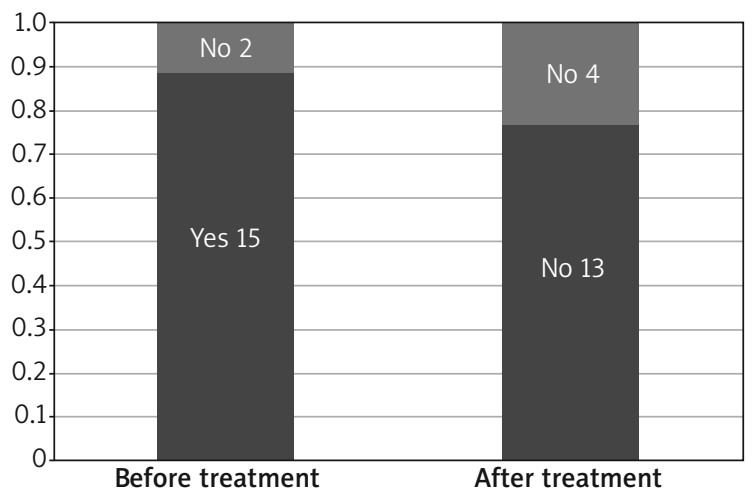

Figure 4. Administration of LABA to the studied patients $(p=0.500)$

ized clinical trials (RCT) with 1380 randomized patients. The review confirmed that omalizumab is effective in reduction of asthma exacerbations after 6 to 24 months of treatment. Statistically significant improvement in forced expiratory volume in $1 \mathrm{~s}$ was observed in three of four RWS after 16 weeks of treatment, in patients under 12 years old who were treated with OCS for maintenance. However, none of RCT showed significant differences between omalizumab and placebo groups regarding increase in $\mathrm{FEV}_{1}$. We did not find statistically significant improvement in $\mathrm{FEV}_{1}$, or FVC ( $p=0.528, p=0.326$, respectively), however this may be due to a small number of observations, comparing to randomized trials. In two RCT and three RWS analysed by Corren et al. ICS dose reduction was observed in omalizumab groups as compared to placebo. In our study we also noticed a significant decrease in ICS use. Reduction in use of OCS was also noticed in two studies $[14,15]$ which were assessed in the systematic literature review, which is consistent with our observations after treatment; OCS were withdrawn in all our patients. Most of the trials assessed in the review used Asthma Control Test (ACT) to assess asthma control $[9,14]$. In our study we used ACQ so we cannot compare our outcomes to other results, however in both tools used, the results show improvement in achieving asthma control. Only one real-world study [14] used mini-Asthma Quality of Life Questionnaire to assess quality of life of the patient treated with omalizumab. In that study improvement in mini-AQLQ outcomes was statistically significant - from 3.5 to 5.9 points, $p<0.0001$. These results were consistent with ours (mini-AQLQ at the beginning and after discontinuation of treatment: 4.37 and 6.10 points, respectively, $p<0.001$ ).

The effectiveness of omalizumab is indisputable and confirmed, while the optimal duration of therapy remains unknown. According to current recommendations established by the coordination team for biological treatment in severe allergic asthma in Poland, after 2 years of therapy patients who reached asthma control, should stop the treatment and be observed for the next 1 year. In case 
of loss of asthma control during the first year of treatment patients can be retreated with omalizumab without new qualification. Odajima et al. performed a study in 38 asthmatic Japanese children aged 7-16 years treated with omalizumab which was an extension to the 24week treatment core study in asthmatic children with severe uncontrolled asthma. The researchers evaluated the long-term safety, efficacy, pharmacokinetics and pharmacodynamics of omalizumab. The median duration of therapy in that study was almost 2 years and 13 patients were treated longer. One interesting observation is that approximately $80 \%$ of patients who were qualified to the extension study, had not adequately controlled asthma in the 16-week follow-up period and free IgE levels returned to baseline in these patients. The authors' observations were similar to these achieved in the study performed by Slavin et al. [16] - omalizumab cessation after less than 1 year of therapy results in loss of asthma control during the next few months. Duration of therapy was differential in our patients (12-48 months) and most of our patients did not experience any exacerbation after omalizumab cessation or had one exacerbation per year.

Lanier et al. published data of their randomized, double-blind, placebo-controlled trial in which 627 patients aged 6 to < 12 years had been enrolled, 421 of them received omalizumab [17]. Efficacy and safety of omalizumab were assessed during 1-year treatment. This trial showed a clinically significant decrease in asthma exacerbations after 24 weeks (reduction by $31 \%$ as compared to the placebo group) in patients treated with omalizumab with further improvement after 52 weeks (reduction of exacerbations by $43 \%$ ). The authors observed consistency of FEV ${ }_{1}$, irrespective of the baseline percent predicted $F E V_{1}$ during the first year of treatment and this data are consistent with our findings. Most patients in the mentioned trial maintained ICS dose throughout the study and this is in contrast to our observations. Moreover omalizumab was assessed as safe with no difference in the number of adverse events as compared to placebo. We did not notice any adverse events in our group of patients.

Molimard et al. performed an observational study in 61 severe asthmatic patients after omalizumab cessation [18]. Patients in this trial were aged 6 to 82 years with 14 patients under 18 years ( 8 children aged $6-11$ years and 6 adolescents aged $12-17$ years). The average duration of treatment with omalizumab was $22.7 \pm 13.1$ months. The authors observed that the longer duration of the therapy, the lower risk of loss of asthma control (69.2\% of patients treated under 1 year experienced loss of asthma control, $59.1 \%$ of patients treated $1-2$ years and $46.1 \%$ of patients treated over 2 years). Summarizing, 20 out of 34 patients who lost asthma control returned to omalizumab therapy with a general good response to treatment.

\section{Conclusions}

Our results are supportive of the existing evidence that omalizumab therapy improves asthma control, reduces OCS and ICS use, and decreases exacerbations in children and adolescent with severe/moderate uncontrolled allergic asthma. Limited data concerning asthma control after omalizumab cessation in children and adolescents are available. Further studies in this age group are required to assess in which underage patients a decision on cessation of omalizumab may be taken.

\section{Conflict of interest}

The authors declare no conflict of interest.

\section{References}

1. Moorman JE, Akinbami LJ, Bailey CM, et al. National surveillance of asthma: United States, 2001-2010. Vital Health Stat 3 2012; 35: 1-58.

2. Kopel LS, Phipatanakul W, Gaffin IM. Social disadvantage and asthma control in children. Paediatr Respir Rev 2014; 15: 256-63.

3. Patel MR, Brown RW, Clark NM. Perceived parent financial burden and asthma outcomes in low-income, urban children. J Urban Health 2013; 90: 329-42.

4. Global Initiative for Asthma (GINA). From the Global Strategy for Asthma Management and Prevention, Global Initiative for Asthma (GINA) 2018. Available at: http://ginasthma. org/2018-gina-report-global-strategy-for-asthma-management-and-prevention/ (13.04.2018).

5. Corren J, Kavati A, Ortiz B, et al. Efficacy and safety of omalizumab in children and adolescents with moderate-to-severe asthma: a systematic literature review. Allergy Asthma Proc 2017; 38: 250-63.

6. Baena-Cagnani CE, Teijeiro A, Canonica GW. Four-year follow-up in children with moderate/severe uncontrolled asthma after withdrawal of a 1-year omalizumab treatment. Curr Opin Allergy Clin Immunol 2015; 15: 267-71.

7. Tat TS, Cilli A. Evaluation of long-term safety and efficacy of omalizumab in elderly patients with uncontrolled allergic asthma. Ann Allergy Asthma Immunol 2016; 117: 546-9.

8. Kulus M, Hébert J, Garcia E, et al. Omalizumab in children with inadequately controlled severe allergic (IgE-mediated) asthma. Curr Med Res Opin 2010; 26: 1285-93.

9. Busse WW, Morgan WJ, Gergen PJ, et al. Randomized trial of omalizumab (anti-lgE) for asthma in inner-city children. N Engl J Med 2011; 364: 1005-15.

10. Deschildre A, Marguet C, Salleron J, et al. Add-on omalizumab in children with severe allergic asthma: a 1-year real life survey. Eur Respir I 2013; 42:1224-33.

11. Kirchnerová OR, Valena T, Novosad J, Teřl M; Czech expeRience Study Group. Real-world effectiveness and safety of omalizumab in patients with uncontrolled severe allergic asthma from the Czech Republic. Adv Dermatol Allergol 2019; 36: 34-43.

12. Schumann C, Kropf C, Wibmer T, et al. Omalizumab in patients with severe asthma: the XCLUSIVE study. Clin Respir J 2012; 6: 215-27.

13. Juniper EF, Guyatt GH, Feeny DH, et al. Measuring quality of life in children with asthma. Qual Life Res 1996; 5: 35-46. 
14. Brodlie M, McKean MC, Moss S, Spencer DA. The oral corticosteroid-sparing effect of omalizumab in children with severe asthma. Arch Dis Child 2012; 97: 604-9.

15. Deschildre A, Marguet C, Langlois C, et al. Real-life long-term omalizumab therapy in children with severe allergic asthma. Eur Respir J 2015; 46: 856-9.

16. Slavin RG, Ferioli C, Tannenbaum SJ, et al. Asthma symptom re-emergence after omalizumab withdrawal correlates well with increasing lgE and decreasing pharmacokinetic concentrations. J Allergy Clin Immunol 2009; 123: 107-13.e3.

17. Lanier B, Bridges T, Kulus M, at al. Omalizumab for the treatment of exacerbations in children with inadequately controlled allergic (IgE-mediated) asthma. J Allergy Clin Immunol 2009; 124: 1210-6.

18. Molimard M, Mala L, Bourdeix I, Le Gros V. Observational study in severe asthmatic patients after discontinuation of omalizumab for good asthma control. Respir Med 2014; 108: 571-6. 